\title{
La salud de los trabajadores y la COVID-19
}

Workers' health and COVID-19

\section{Fernando G. Benavides ${ }^{1,2}$}

${ }^{1}$ Centro de Investigación en Salud laboral, Universitat Pompeu Fabra, IMIM PSMar, Barcelona, España. ${ }^{2}$ CIBER de Epidemiología y Salud Pública, Madrid, España.

Fechas $\cdot$ Dates

Recibido: 2020.04.04 Aceptado: 2020.04.10 Publicado: 2020.04.15

\section{Correspondencia · Corresponding Author}

Fernando G. Benavides

fernando.benavides@upf.edu 
La pandemia de la COVID-19 está afectando a toda la sociedad, y de manera especial a los trabajadores y a las empresas. Los ajustes de plantilla, algunos temporales, la reducción de horarios, el teletrabajo, son algunos de los cambios masivos que se están produciendo consecuencia directa de la pandemia. Cuánto quede de todo esto estará por ver ${ }^{(1)}$.

Hay muchas lecturas y muchos niveles de análisis de esta crisis, uno de ellos es el cuestionamiento del mercado (y su famosa mano invisible) frente al papel del Estado, como último salvavidas del conjunto de la sociedad. Entre ambos, Estado y Mercado, se sitúa modestamente la salud laboral, cuya misión es la protección de la salud de las personas que trabajan. Un objetivo que hay que implementar en las empresas, de acuerdo como mínimo con una regulación legal muy detallada y controlada por organismos capaces de detectar las infracciones y sancionarlas.

Esto nos sitúa, ni que decir tiene, en el ojo del huracán. Desbordados y desconcertados asistimos a una situación extraordinaria, para la que no estábamos preparados. Hemos tenido que sacar de la mochila del colegio las virtudes "teologales" de la templanza y la fortaleza para imaginar y consensuar soluciones ad hoc, que a continuación se quedaban cortas o sencillamente eran erróneas. Hemos comprobado una vez más que el ensayo/error es la mejor manera de avanzar en medio de la oscuridad. Y ha sido, valga la pena mencionarlo, una oportunidad para que la salud laboral asuma un liderazgo obvio que le corresponde en las empresas y las instituciones públicas. Lo que se traduce en muchas empresas en la participación de los Servicios en los comités de crisis, junto con el director o la directora general.

Efectivamente, al no tener inmunidad frente al SARS-CoV-2, y no disponer de vacuna de momento, la única medida preventiva efectiva consiste en inducir, con el apoyo explícito de los Estados -en forma de estado de alarma en España o su equivalente en los diferentes países del mundo-, comportamientos preventivos extraordinarios, como que las personas se queden confinadas en sus domicilios, además de cerrar escuelas, comercios, cines, bares, etc. y finalmente empresas de actividades no esenciales. Lo cual, sorprendentemente, se está respetando por la inmensa mayoría de los ciudadanos y empresas. La colaboración, siguiendo el instinto de la especie, se impone de manera natural. Nuestra supervivencia depende de ello. El aplauso -también para decir que seguimos vivos - es un rito diario a las $8 \mathrm{pm}$.

En resumen, la distancia física (más de 2 metros) está siendo la medida preventiva más eficaz para reducir la reproducción del virus (índice RO), la incidencia de la enfermedad (tasa de ataque) y, finalmente, la tasa de letalidad(2). Los sistemas de vigilancia epidemiológica en salud laboral están resultado instrumentos decisivos, tanto para la gestión de casos y contactos, como para la predicción de escenarios que permita gobernar la pandemia a sus distintos niveles.

Pero la condición sine qua non para que esas medidas de confinamiento resulten aplicables es que haya actividades que sigan funcionando en lo que se ha llamado, y todo hemos descubierto, servicios esenciales. El confinamiento total no era ni es posible, pues sin la panadería o el supermercado o, aún más importante, los centros sanitarios -y toda su cadena de suministros- simplemente no funcionaría. Los 
ciudadanos no aceptaríamos irnos a casa y esperar tranquilos a que todo acabe. La alteración del orden público y su control estarían a la orden del día.

En esta doble decisión, confinamiento de lo no esencial y actividad de lo esencial, las medidas prevención de riesgos para proteger a los trabajadores que continúan sus tareas han sido fundamentales. Digámoslo alto y claro, los servicios de prevención son una parte esencial para el mantenimiento del estado de alarma. Algo que no ha sido suficientemente reconocido, sea por la torpeza de nuestra administración y/o de nuestra profesión. Hagámoslo, sin falsa modestia. El final de la pandemia, con el menor número de fallecidos, solo será posible si la prevención de riesgos laborales funciona. No solo para la gestión de los equipos de protección individual (EPI), también, y aún más importante, en la monitorización de los efectos de los riesgos psicosociales fruto de los cambios de horarios, el teletrabajo, etc. sobre la salud mental y física.

Ahora vemos que son muchas y diversas las ocupaciones que son esenciales: cajeras de los supermercados, repartidores de todo tipo de mercancías, barrenderos, conductores de autobuses o metros, etc., etc., etc., pero está claro que los sanitarios ocupan un lugar especial. Ellos son los héroes de esta crisis. Como señalaba la editorial de este mes del Scandinavian Journal of Work and Enviromental Health, "... los profesionales sanitarios, médicos, enfermeras, auxiliares, camilleros, conductores de ambulancia, etc., están a la vanguardia de la batalla contra la COVID-19. Ellos son los que atienden a las personas enfermas. Ellos hacen frente al sufrimiento y a la muerte"(3). El efecto sobre la salud mental de los trabajadores sanitarios es ya una prioridad preventiva(4).

Ahora bien, para la mayoría de ellos han faltado, especialmente al inicio cuando era más probable el contagio, los EPIs, desde mascarillas y guantes a batas y gafas, sean en los hospitales o en los mercados centrales de cada ciudad. Infringiendo con ello las normas vigentes y los principios básicos de prevención, recogidos tanto en la Ley 31/1995, como en el RD 664/1997, sobre riesgo biológico. Además, esta situación de desprotección supone un incremento del riesgo de contagio a otros compañeros o clientes, pacientes en el caso de los trabajadores sanitarios. Una situación que ha llevado a plantear la aplicación del artículo 21 de la Ley de prevención de Riesgos Laborales, en que por riesgo grave e inminente la persona trabajadora puede negarse a trabajar. Lo que ha supuesto un grave dilema ético, además de legal, de atención a pacientes que están o pueden estar infectados. El resultado de estos fallos, y aún más grave la falta anticipación y su preparación, ha supuesto que alrededor del $25 \%$ de los casos han ocurrido en personal sanitario(5).

Afortunadamente, poco a poco se han ido estableciendo protocolos razonables ${ }^{(6)}$ y llegando los EPIs, a un ritmo demasiado lento en estos momentos, para proteger a las personas que debían seguir trabajando para que el confinamiento comunitario fuera posible. Una de estas medidas ha sido el reconocimiento de la incapacidad laboral por contingencia profesional (sin necesidad de cadencia para recibir la prestación y un beneficio económico mayor), dando naturaleza laboral a la enfermedad, mientras la persona ha estado confinada, sea por sospecha o caso 
confirmado, facilitando con ello la contención de la propagación. Una medida que no se puede aplicar a personas con trabajo informal sin cobertura de la prestación.

Pero si la escasez de EPIs, y su producción accesible, ha sido una de las carencias más evidentes, que habrá que revisar para prepararnos para las siguientes pandemias con reservas estratégicas de material adecuado, menos obvio, pero más básico, ha sido la falta de información que ayudará a la gobernanza de la crisis sanitaria en las empresas y desde los gobiernos. Sin información es ir sin linterna en medio de la oscuridad. La vigilancia epidemiológica, sea para le gestión de casos y contactos, como para la gestión de los recursos en las empresas han fallado. La escasez de pruebas diagnósticas ha dificultado aún más esta gestión, especialmente de los contactos. Definiciones básicas como qué es un caso, o contacto, sea de sospecha o confirmado, el aislamiento y el alta epidemiológica, no han sido establecidos con claridad al inicio de la crisis, y mientras fue así los sistemas de información, cuando existían, proporcionaban información poco fiable.

Muchas son las lecciones que hemos ido aprendiendo en la medida que la pandemia avanzaba, pero son muchas más las que aún nos quedan por aprender. La primera a reconocer es que todos nos hemos equivocado, tantos políticos, gestores como profesionales. La segunda es que solo con la colaboración y la critica constructiva podemos avanzar y prepararnos para la próxima(7). No es aceptable decir que yo ya lo dije. Es de tahúr adivinar el pasado desde el futuro. A toro pasado todos somos toreros.

En este sentido, y cuando la curva de la pandemia parece aplanarse, ahora hemos de pensar en el día de después, y prepararnos para la vuelta a la normalidad que, como ya sabemos, será escalonada. Este será el momento de comparar y evaluar los efectos de cada medida, de manera sistemática, y publicando los resultados. Todos hemos de aprender, los que la hemos vivido con gran intensidad, como en Barcelona, y los que han tenido la suerte de vivirla de manera más leve. Los que hemos tenido familiares o amigos que han fallecido o los que han tenido la fortuna de sobrevivirla sin pérdidas de allegados. La pandemia no ha afectado a todos por igual, por supuesto a los mayores versus los jóvenes, pero tampoco a los que viven en $50 \mathrm{~m}^{2}$ versus los que viven en más de $100 \mathrm{~m}^{2}$. Los países de renta alta versus los de renta media y baja.

Ha sido una experiencia única, un experimento "natural", de toda la humanidad. Quien crea que esta pandemia inicia un época de retorno a la "aldea" se equivoca. Es verdad que la velocidad de propagación del virus es en parte consecuencia de la globalización, por el intercambio de personas y mercancías, pero también ha sido la globalización, empezando por China, la que ha permitido dar una respuesta rápida y eficaz contra la pandemia. Necesitamos más democracia global, con instituciones multilaterales, como la Organización Mundial de la Salud, con más recursos y con más capacidad operativa, no más nacionalismos y autoritarismo de viejo cuño.

En ese día de después, hemos de prepararnos para la anunciada recesión económica, por lo que los servicios de prevención deben estar atentos, y las empresas deben poner en valor sus beneficios durante la crisis sanitaria. De nuevo, la re- 
cesión no debe servir para ajustar los costes por lo más básico, la salud de los trabajadores ${ }^{(8)}$. El Estado, también con toda su fuerza y legitimidad democrática, debe vigilar para que la salud de los trabajadores esté protegida. Ese derecho ya estaba y está en las Constituciones. Por supuesto, más allá de la salud laboral está la salud pública y las políticas de protección social a las personas que se queden sin trabajo, con medidas como la renta básica. Pero eso ya es otra historia, aunque es parte de la misma historia de todos.

Agradecimientos: Este manuscrito se ha visto enriquecido con los comentarios de Jordi Delclós, de la Escuela de Salud Pública de la Universidad de Texas, y Marcelo Amable, de la Universidad Nacional de Avellaneda de Argentina, lo que no exime al autor de los posibles errores o imprecisiones.

\section{Referencias}

1. Hurley J. Coronavirus: A labour market earthquake. Disponible en: https://www. eurofound.europa.eu/publications/blog/coronavirus-a-labour-market-earthquake. Accedido 4 abril 2020.

2. Anderson R, Heesterbeek $H$, Klinkenberg D, Hollingsworth TD. How will country-based mitigation measures influence the course of the COVID-19 epidemic? Lancet. 2020;325:931-4.

3. Burdorf A, Porru F, Rugulies R. The COVID-19 (Coronavirus) pandemic: consequences for occupational health. Scand J Work Environ Health Online-first -article. doi:10.5271/sjweh.3893.

4. Sim MR. The COVID-19 pandemic: major risks to healthcare and other workers on the front line. Occup Environ Med 2020. Epub ahead of print. doi:10.1136/ oemed-2020-106567.

5. Red Nacional de Vigilancia Epidemiológica. Centro Nacional de Epidemiologia. Instituto de Salud Carlos III. Informe Covid-19, n 21, 6 abril 2020. Disponible en: https://www.isciii.es/QueHacemos/Servicios/VigilanciaSaludPublicaRENAVE/ EnfermedadesTransmisibles/Paginas/InformesCOVID-19.aspx. Accedido 7 abril 2020.

6. Procedimiento de actuación para los servicios de prevención de riesgos laborales frente a la exposición al SARS-CoV-2, de 30 de marzo de 2020. Disponible en: https://www.mscbs.gob.es/profesionales/saludPublica/ccayes/alertasActual/ nCov-China/documentos/PrevencionRRLL_COVID-19.pdf. Accedido: 4 abril 2020.

7. Benavides FG, Porta $M$, et al. Ciencia y política en tiempos de incertidumbre. El Pais, 27 de marzo 2020. Disponible en: https://www.upf.edu/inicio/-/asset_publisher/VqFup2qZdhmS/content/id/233816835/maximized\#.XokRV9P7RQI. Accedido 4 abril 2020.

8. Benavides FG. Crisis económica y salud laboral. Arch Prev Riesgos Labor. 2009;12:113-114. 